\title{
A Study on the Cultural Characteristics of Korean and Chinese Languages
}

\author{
Jung Soon Cho1)
}

\begin{abstract}
Recently, the number of foreign students coming to Korea has been increasing. It is no exaggeration to say that the Korean language is growing as a global language As a result, the number of students studying abroad has increased over the years. The number of foreign students surpassed 100,000 , with 85,923 in 2013, 104,262 in 2016, and 166,401 in September 2018.It is no exaggeration to say that this is the second Hallyu. To keep up with the heat, the government is targeting 200,000 people by 2023 . Therefore, the study aims to make Chinese learners learn and use Korean-specific language culture by recognizing differences in language culture beyond simply comparing their mother tongue with their target language. In other words, learning and using Korean is understanding not only the Korean language itself but also the cultural background inherent in the Korean language, and learning Korean means learning the value system and behavior patterns of Koreans. In response, the study plans to prepare a plan to efficiently conduct Korean language education, which includes social and cultural elements, considering the characteristics of Chinese learners. Through the comparison of language culture between Korean and Chinese, specific data on the need for language culture education for Chinese learners were compared.
\end{abstract}

Keywords : Part of Speech, Language Culture, A Pronoun, Numeral, Title, Verb

\section{Introduction}

As globalization progresses, the number of foreign language learners got accelerated in an increasing manner. The recent surging popularity of Korean pop culture has been sparked by a singing group called BTS. This can be one of the reasons for the rapid increase in a number of Chinese learners of Korean language. While their primary focus may be wanting to understand the lyrics of Korean songs, they are categorized as regular language students based on their motivation to learn and communicate in Korean. The desire to learn and communicate in Korean implies that they not only want to understand the Korean language, but also the cultural backgrounds embedded in the language. It also implies that they want to understand the value system and behaviors of Korean people. Namshim[1]. Therefore in order to

Received(December 16, 2018), Review Result(1st: January 4, 2019, 2nd: February 8, 2019), Accepted(March 10, 2019)

1) (Professor) 46958 Free Arts College, Silla Univ. Guebeb-dong, Sasang-gu, Busan, Korea

email: siyecao@silla.ac.kr 
communicate effectively, it is necessary to learn and understand Korean and Chinese nouns, pronouns, adjustive, and such in a precise and descriptive manner. So the purpose of this essay is to ensure successful communication with Koreans by acquiring the characteristics of the language and culture inherent in the language.

\section{Comparison of Korean and Chinese Language Culture}

\subsection{Languages Related to Nouns}

In Korean, different titles are used depending on age, status, and relationships. Lee Kwan-gyu [2]. The classification depends on the scholar. We will add an ending called ' $\sim$ 씨'. For example, family name plus given name followed by 씨, or given name 씨, or family name 씨. Family name 씨 is widely used when addressing non-professional people. On the other hand, those in official positions are called “ 님" such as "총장님, 원장님, 교수님, 부장님" after the title of the job he holds. If an addressee is well respected, then even if the addresser is older than the addressee, the addressee is referred to as " 님(Mr. ) like "이 박사님, 박사님, 긴 원장님". And when referring to strangers, it is common to call a person by '선생님 (teacher). In Korean society, he or she is also commonly addressed by '사장님(president). When a superior calls his subordinates, he says '자네' or 'last name 군' to male and 'last name양' to female. When addressing to an elderly person, he would say '어르신'. When addressing to children, instead of just given name, he would say by adding an ending suffix like 'given name아/야. Sometimes when someone is called or asked, regardless of age, relationship and social status, '여기요, 저기요' is used. At times, although they are not related, people use titles such as an aunt, sister, uncle to express their closeness. Oh Jeong-ran[3]. In universities, students address by saying 'senior' or 'younger' based on the years they admitted to show verticil relationship in Korea. It is the same in company settings as well as in a military environment. Also when a parent of a child introduces his or her child to another person, the child is called 'son' or 'daughter. However, when addressing other people's child, the child is called '아드님' or '따 님' to show some level of respect. As such, the use of titles in addressing in Korean is very complicated, making it even more difficult for foreign learners to use them. Kuo Ke Yin[4]. But in China, regardless of whether they are older or younger than the speaker, they use the 'name' or 'you'. Regarding ' 군' and ' 양'in Korea, put in the '小+family' and 'Name+同學/小 姐'. If the listener is older than the speaker, '老/ 大+성' is usually used to call young people 
friendly.

\subsection{Languages Related to Pronouns}

In the Korean language, personal pronouns are only used on people but not on objects or animals. Which means that if an animal or object is being referred, the actual name of such animal or object is directly used. However, in the Chinese language, the appropriate pronouns are used separately when they represent objects and animals. Instead of omitting the subject for most Koreans to name specific people, Sun Ruj Ian[5]. Chinese must use first and second-person jargon. It is also used to refer to a group of people when they make a call or receive a call, which is also common between Chinese and Korean. Looking at the Korean language (a government detective 이/그/저) '이-' is a place close to the speaker, '그' is a place close to the listener, and '저' refers to a place far from both the speaker and the listener. On the other hand, Chinese is indicating who is being ordered by using a combined dichotomy. 這 - 와 '那- / 那-'. And the unique language culture of Korean allows them to communicate on the phone only by indicating its location or the direction that they each other well, rather than by indicating by the person's name on the phone. For example, 'please tell him that the call is from Sasang (place not name)' to indicate who you are. Also when in a restaurant or in a coffee shop, patrons call shop's employees by saying '여기요(here)' or '저기요 (there)' in order to indicate that where you are and when you need their service. In addition, by calling one's wife 'Busan 댁' for example, a city name Busan is used to refer to a place where the person is born or the person who got married is from that city. Therefore, this language culture can only be understood and acquired when Chinese learners have long been in close contact with members of the Korean spoken society.

\subsection{Language Culture Related to Verb}

The most notable characteristic of Korean verbs is that it has verbal conjugation. It has various suffix methods along with verb stem. As it conjugates, it changes its functions. The verb stems do not change based on personal pronouns, singular or plural, or gender. The verb itself does not change entirely, however, suffix changes based on tense and writing style (mood). The characteristics of the verb are as follows. First, the subject words are sometimes omitted in a sentence. Korean's daily conversations will reveal that they only use the verb to express the whole without any subject or object in a sentence. 
A: (It is snowing, to school) would you like to go?

B: you go?

A: It's snowing (you go)?

B: I'm busy, what to do?(Got To go)

A: (Because it's snowing heavily, to the park) go later.

B: No, anyway I have to go (to school).

Second, 'ㄹ irregular verbs' are often used as regular verbs.

놀다: 놀은/ 논, 벌다: 벌은/ 번, 살다; 살은/ 산, 이끌다: 이끌은/ 이끈 등

Third, intentional connection: in front of '-려고,' people tend to pronounce '르'. 아들이 밥을 잘 안 \{먹을려고, 먹으려고\} 해서 큰일이에요. (It's a big deal that the kids are not eating $\rightarrow$ 먹 을려고: 먹-을-려-고, 먹으려고: 먹-으려고 are going to eat)

Wang Chen-jen[6]. Among the grammatical features of the Chinese verb, the most different feature of the Korean language is that in the structure of the first verb + object, the object is the usage of the verb or adjective, and the noun and pronoun are not. 進行(研究), 開始(學習), 加以(批評), 希望(成功), 感到(高興), 感覺(不舒服) It takes the form of verb+ (verb/former). This means that the format is only in Chinese, an isolated case that is not found in the Korean verb, which is considered a deadlock. In Korean, "We start our Chinese class at 8 every day" is written or said in Chinese as "我們每天八点開始(上)漢語課/ The verb '開始' will take another verb as its object, as it says, '上' instead of starting Chinese classes. Second, one of the characteristics of Chinese verbs is that they can be attached or separated. The verb 'sleep' can be used by attaching '我剛才睡覺了' (I just slept) or separating it from '我剛才睡了一會儿覺.' This is derived from the architectural features of Chinese words. Chinese can be divided into simple and composite languages, and the compound word can be divided into additional and complex forms, combining two or more morphemes. Two elements of compound words, $\mathrm{X}$ and $Y$, can be in a form of the following five types of structural relationships; subject-predicate, homogeneous, descriptive, complementary and combined.

\subsection{Language Culture Related to Cardinal and Ordinal Numbers}

When looking at cardinal and ordinal numbers in languages, we may see different cultures related to certain numbers, and the following discusses the difference between Kyo Ji Yeon[7]. 
Chinese and Korean languages. First, ' 3 ' often appears in entertainment, using the word 'three times' as a number. In particular, the situation of winning or losing a game, people want to give more chances until winning 3 times instead of winning only once to claim a victory.

Second, ' 4 ' is a number that Koreans dislike very much. This is because it sounds like the pronunciation as the Chinese character, death. Therefore, the number of floors in apartment buildings or department stores, and the $4^{\text {th }}$ floor is marked "four" instead of " 4 " in English. Third, it is believed that " 7 " is a lucky number because it is called "Lucky Seven" in English. Fourth, '10', ' 100 ' and ' 1000 ' are the favorite numbers of Koreans because they have some sort of a meaning of fullness or completeness. For example, 'all trees can be cut down within 10 attempts.' is said as an encouragement. The '100th day' is celebrated to mark the 100th day of the baby's birth. '100 roses' are also given to a lover to congratulate the 100th day of togetherness. Fifth, Koreans use the word 'billionaires' when it refers to people with a lot of money. The number 'billion ( 1 million)' is used to mean countless and 'very rich'. On the other hand, the Chinese favorite number is ' 8 . The reason is that the pronunciation of ' 8 ' in Chinese is 'ba', which is 'earn money'. This is because it has a similar pronunciation to "pachai," which means to accumulate wealth. The price list for household items also shows a price tag ending with 8's, including 118 won, 888 won, and 998 won. It seems that the Chinese people feel better when they see number 8 in price, without even realizing the price is a little expensive. Also, they love to have ' 8 ' for home phone numbers and mobile phone numbers as well as for automobile plate numbers even by paying huge premiums in using ' 8 '. Futhermore, 6 is a number that symbolizes the road image and sounds the same as "liu," which means "smooth without any hardship". On the other hand "9" is the Chinese pronunciation of "Jiu," which means "long, eternal." As discussed earlier, the differences in language culture of Korean and Chinese were shown through numbers. As you can see, for Koreans meaning is important, while Chinese puts its value in the sound which is related to the pronunciation of numbers and things. In addition, Chinese have especially unique language culture that distinguishes even from odd numbers. When giving gifts, be sure to offer even amount for a wedding gift. However, as an exception, for condolence, an odd amount of money is offered.

\subsection{Language Culture Related to Adverb}

There are monophonic and abstinence in adverbs. They were modeled and created by mimicking the actual sounds from the movement or the shape of a person, an animal, or an 
object. It plays a big role in expressing the vitality, aesthetics and intuition of a language. Various nuance symbols are often used as they can express feelings and beautify in details and they are flexible in expression. Hence, the adverbs which were originated from various sounds and shapes are often used to describe in detail. It has been noted that Chinese learners often face challenges with descriptive adverbs such as monophonic adverbs since they were developed as Korean. They are rarely used because they are unfamiliar and awkward Korean words for the Chinese. Cho Jung-soon[8]. Language education is not as easy as expected, and it is also a difficult part for Chinese learners. For example, it is difficult for Chinese learners to detect the difference between the phonological characteristics of the echolocation and the phonetic vowels of the echoes, or some formations are not translated into their native languages at all. In particular, Chinese is a relatively limited language with monophonic and abstinence expressions, and thus Chinese learners often make mistakes in the use of artificial words and modifiers. Errors in the use of a foreign language can be largely divided into two reasons; due to the influence of the mother tongue and those based on the target language.

First, errors due to limitations and sounds of the mother tongue

(1) Rooster cries 'wo-wo'.

(2) Fly shouts out 'wing-wing'.

(3) Mouse goes 'tch-tch'

(4) Door closed sounding' peong'

The errors in the above example are those that are expressed in Chinese as '喔喔,' '嗡嗡,' '吱 吱,' and '呼' as the sounds of the doors closing.

Second, the error is noted due to target language effect as shown below

(1) The kid is eating a candy smilingly.

(2) The kid got up rapidly and went to the bathroom.

(3) The weather today is cold and gently windy.

(4) Despite learning Korean for the first time, the student's pronunciation of words were clear.

In (1), 'smilingly' is used to express a big smile. It is misused as in eating. In (2), 'rapidly' was misused in place of 'suddenly'. In (3), the adverb 'gently' is used to represent a large bird flying in the air, to show the wind blowing, and in (4) to use 똑똑('clearly)' in 

combination with '똑똑(smart)'. It is believed that the mistakes of the words are evident and it is harder for learners to master the Korean language than they had thought. Although Korean words contain many Chinese characters, it is still very difficult for Chinese learners to master the Korean language due to words that are monophonic and abstinence in nature. Therefore, in order for Chinese learners to learn effectively, the use of not only textbooks but also the children's literature, children's textbooks, cartoons, fairy tales, and advertisements in classes highly recommended. Moreover, the cultural psychology of the two countries shows that Koreans are more emotional than the Chinese. A good example is the comparison of Korean movies and Chinese movies. While Chinese movies are characterized by quick and direct action and development, Korean movies have relative appeal for emotion. Therefore, the delicate language culture makes Chinese people get impressed in Korean dramas and movies. This sophisticated language culture can also be a genetic factor which is responsible for the popularity of Hallyu worldwide.

\section{Conclusion}

Effective foreign language education is a process of developing the ability to recognize and interpret equally the material world through the language culture system of the target language. This study compared the linguistic and cultural characteristics of Korean and Chinese languages, taking into consideration of unique titles of Korean and Chinese characteristics. When teaching, it must be recognized that once the language culture education is firmly established, the Chinese and Korean people will be able to communicate successfully. In particular, the language culture of Korea and China can provide appropriate expressions in communication. Furthermore, understanding of both languages through language cultures related to their nouns, language culture related to their pronouns, language culture related to their verbs, and language culture related to their adverbs will enhance affluent communication and effective learning. In that language, culture education is presented not only in the text but also in the corresponding actions. It is necessary to reflect the thoughts and reflections of people who use the target language for successful education to increase the understanding and to utilize the language culture. Therefore, effective language culture education for Chinese learners requires careful analysis and awareness from educators. 


\section{References}

[1] G. S. Nam, Y. G. Ko, Standard Korean Literature, Top Publishing Company, (2009)

[2] K. G. Lee, Korean grammar theory for Korean language education, Jipmundang, (2005)

[3] J. R Oh, Comparison of Korean, Chinese, and Language Culture as a Foreign Language, Pagijong Press, (2011)

[4] K. Y. Kuo, Chinese language and traditional Chinese culture, China People's University Press, (1993)

[5] R. I. Sun, China's excellent traditional cultural and educational centre, China Light Industry Press, (2008)

[6] C. J. Wang, learner's intermediate culture system, World Chinese teaching and learning, (1995), October 12-15; beijing, China.

[7] J. Y. Kyo, The content and practice of Korean cultural education for Kyojiyeon and Chinese learners, Kwangwoon University, Master's thesis, (2010)

[8] J. S. Cho, Comparative Study on the Education Contents of Korean Language and Culture, Silla University, Ph.D dissertation, (2013) 